\title{
DO ECONOMICS DEPARTMENTS WITH LOWER TENURE PROBABILITIES PAY HIGHER FACULTY SALARIES?
}

\author{
Ronald G. Ehrenberg, Paul J. Pieper, and Rachel A. Willis*
}

\begin{abstract}
The simplest competitive labor market model asserts that if tenure is a desirable job characteristic for professors, they should be willing to pay for it by accepting lower salaries. Conversely, if an institution unilaterally reduces the probability that its assistant professors receive tenure, it will have to pay higher salaries to attract new faculty. Our paper tests this theory using data on salary offers accepted by new assistant professors at economics departments in the United States during the 1974-75 to 1980-81 period, along with data on the proportion of new Ph.D.s hired by each department between 1970 and 1980 that received tenure in the department or at a comparable or higher quality department within the first eight years of receipt of their Ph.D.s. We find evidence that supports the hypothesis that a tradeoff existed. Equally importantly, departments that offered low tenure probabilities to assistant professors also paid higher salaries to their tenured faculty. We attribute this to low tenure probabilities inducing higher effort from assistant professors and thus leading to higher productivity of faculty ultimately promoted to tenure.
\end{abstract}

\section{Introduction}

$\mathrm{R}$ ISING TUITION levels in American private colleges and universities, which have far exceeded the rate of inflation for over a decade, have increasingly brought these institutions under close public scrutiny and led to calls for their increased efficiency and accountability. These pressures have been exacerbated by a number of factors, including the abolition of mandatory retirement for faculty, which became effective in January 1994. The end of mandatory retirement has led to fears that colleges and universities will become increasingly populated by an aged nonproductive heavily tenured professorate whose relatively high salaries will place increased financial burdens on institutions and whose failure to retire at reasonable ages will reduce the ability of institutions to diversify their faculty along race, gender, and ethnic lines. ${ }^{1}$ In fact, during the 1996-97 academic year, $65.6 \%$ of all full-time college and university faculty members in the United States had tenured appointments. ${ }^{2}$

Economists have provided a variety of explanations, in

Received for publication October 27, 1995. Revision accepted for publication October 9, 1997.

* Cornell University and National Bureau of Economic Research; University of Illinois-Chicago; and University of North Carolina-Chapel Hill, respectively.

We are grateful to C. Elton Hinshaw, Secretary-Treasurer of the American Economic Association, for granting us access to individual institutional responses to the AEA's annual salary survey of economics departments, to Charles Scott at Loyola College (Maryland) for providing the data to us, to Kari Alexander and Jaroslava Mykula for research assistance, and to Daniel Hamermesh, two anonymous referees, and the editor for their comments on an earlier draft. Because of confidentiality requirements, these data cannot be made available to other researchers for replication purposes.

${ }^{1}$ That these fears may not be justified is discussed by Rees and Smith (1991) and Hammond and Morgan (1991) who evaluate the likely effect of the abolition of mandatory retirement on faculty retirement rates, and by Hamermesh (1994), Rees and Smith (1991), Levin and Stephan (1991), and Stephan and Levin (1992) who study and summarize studies of life-cycle faculty productivity differentials.

${ }^{2}$ See American Association of University Professors (1997, table 12). addition to traditional academic freedom ones, to justify a tenure system. These include that by providing a form of job security for tenured faculty, the system encourages senior faculty to share their knowledge with younger colleagues and to hire as colleagues those younger applicants who they perceive to be most talented, that it serves as a "tournament" that provides an incentive for nontenured faculty to work harder than would otherwise be the case, and that it solves the incentive problem needed to get talented people to obtain very specialized and expensive training that may be useful only in well-defined and narrowly specialized tasks. ${ }^{3}$ In addition, the fact that tenure is typically accompanied by increasing salaries over the life cycle, even though there is evidence that productivity eventually declines with age, can be rationalized as part of a life-cycle incentive compensation scheme that provides incentives for both nontenured and tenured faculty to exert more effort than otherwise would be the case. ${ }^{4}$

However, the abolition of mandatory retirement for college and university faculty has caused many people (primarily outside of academia) to focus on tenure's costs. Proposals to eliminate or modify tenure have been put forth, and one institution recently unilaterally eliminated tenure for its faculty. ${ }^{5}$ Absent from the discussion of these proposals has been an awareness of the simplest competitive labor market model that asserts that if tenure is a desirable job characteristic for professors, they should be willing to pay for it, by accepting lower salaries. ${ }^{6}$ Conversely, according to this theory, a reduction in tenure probabilities should reduce the attractiveness of faculty positions and thus increase the salaries necessary to attract people into doctoral study and academia.

Do departments that offer new assistant professors low tenure probabilities actually pay higher starting salaries for new assistant professors than otherwise comparable departments who offer higher tenure probabilities? This paper first addresses this issue. It uses salary offers accepted by new assistant professors at economics departments in United States colleges and universities during the 1974/75 to 1980/81 periods, along with data on the proportions of new Ph.D.s hired by each department between 1970 and 1980 that received tenure in the department or at a comparable or higher quality department within the first eight years of

\footnotetext{
${ }^{3}$ See, for example, Stigler (1984), Carmichael (1988), Lazear and Rosen (1981), McPherson and Winston (1993), and Siow (1994).

${ }^{4}$ Lazear (1979). The incentive for tenured faculty to exert more effort than would otherwise be the case follows in this model from tenure being an implicit contract which at best provides a promise that nominal salaries will not be reduced. "Nonperformers" thus face the possibility of zero nominal salary increases and their real salaries being reduced each period by the rate of inflation.

${ }_{5}^{5}$ Henderson (1994) and Bennett (1994).

${ }^{6}$ This theory, which goes back at least to Adam Smith, is summarized in Ehrenberg and Smith (1997, chapt. 8)
} 
receipt of their Ph.D.s, to estimate if a tradeoff did exist between starting salaries and tenure probabilities during the 1970s. ${ }^{7}$

A tradeoff may also exist, however, between the tenure probabilities faced by assistant professors and the salaries a department pays to tenured faculty for two reasons. First, ceteris paribus, lower tenure probabilities for assistant professors imply either that a department will have fewer tenured faculty in steady state or that it will hire a greater share of its tenured faculty from faculty already employed at other institutions. Faculty hired away from other institutions often earn higher salaries than those promoted from within because the former must be compensated for their monetary and psychological cost of mobility and induced to leave their original institution. ${ }^{8}$ To the extent that lower tenure probabilities for assistant professors do imply that a greater share of tenured faculty were hired away from other institutions, one should therefore also expect to observe higher salaries for tenured faculty in this situation, other factors held constant.

Second, low tenure probabilities at an institution may induce new assistant professors to work harder so that if they fail to get tenure at the institution, they will have a stronger record to increase their employability elsewhere. This stronger record, however, will also increase their productivity and value to their original department and hence the salary it will have to pay them if they are granted tenure. Put another way, a low expected tenure probability can be thought of as being part of a Lazear and Rosen (1981) type of tournament with a greater reward for winning. We test both these hypotheses by using the AEA data, which also contained information on average salary by rank for economics department faculty, to estimate if a tradeoff existed between average salaries of tenured faculty and the tenure probabilities offered new assistant professors during the 1970s.

To motivate the empirical work that follows, the next section presents a simple conceptual model of the salarytenure probability relationship. Section III presents descriptive statistics on the starting salaries paid to assistant professor of economics during the 1974-1980 period and estimates of the tenure probabilities they faced. Our empirical estimates of the starting salary-tenure probability relationship appears in section IV. Section V briefly discusses the relationship between the tenure probabilities faced by new assistant professors in a department and the salaries of tenured faculty in the department. Empirical estimates are provided that indicate that low tenure probabilities require an institution to pay also more for tenured faculty. Finally, the paper ends with a discussion of our findings, alternative hypotheses that are consistent with these findings, and the directions in which future research might proceed.

\footnotetext{
${ }^{7}$ As will become clear later, the sample period is dictated by data availability.

${ }^{8}$ For evidence that tenured faculty hired from the outside tend to earn more than tenured faculty promoted from within, see Ransom (1993).
}

\section{A Simple Conceptual Model of the Tradeoff between Tenure Probabilities and Starting Salaries in Academia}

To motivate the empirical research, consider the following simple conceptual model. Risk-neutral new Ph.D.s, who are all of equal quality, are confronted with job offers from universities of equal quality. ${ }^{9}$ These offers vary only in their pecuniary compensation and their probability of receiving tenure. Individuals are assumed to have professional careers that last $N$ periods, and the tenure decision is made at each institution after a probationary period of $P$ years.

During the probationary period an individual is assumed to receive a fixed salary per period of $W_{\mathrm{pi}}$ at institution I and to receive a benefit package at that institution which increases her compensation by a multiple $b_{\mathrm{i}}(>1)$. The individual believes that the probability of receiving tenure at institution $\mathrm{I}$ is $T_{\mathrm{i}}$ and that if she receives tenure, her salary per period will be increased by a multiple $g_{\mathrm{i}}(>1)$ to the level $W_{\mathrm{Ti}}=W_{\mathrm{Pi}} g_{\text {i }}$, which will then remain constant for the remainder of her worklife. If the individual fails to receive tenure, she will receive a lower compensation package in alternative employment of $C\left(C<W_{\mathrm{Ti}}\right)$. Finally, for simplicity, voluntary mobility across institutions is ignored. If the individual receives tenure, she is assumed to remain with the institution throughout her career. Several of these assumptions are generalized in a later section.

Given these assumptions, the individual's expected present value of compensation if she chooses employment initially at university $\mathrm{I}$ is

$$
\begin{aligned}
V= & \int_{0}^{P} W_{\mathrm{Pi}} b_{\mathrm{i}} \mathrm{e}^{-\mathrm{rt}} \mathrm{d} t+\int_{P}^{N}\left[\left(T_{\mathrm{i}} W_{\mathrm{Pi}} b_{\mathrm{i}} g_{\mathrm{i}}\right)\right. \\
& \left.+\left(1-T_{\mathrm{i}}\right) c\right] \mathrm{e}^{-\mathrm{rt}} \mathrm{d} t
\end{aligned}
$$

or

$$
\begin{aligned}
V= & \frac{W_{\mathrm{Pi}} b_{\mathrm{i}}}{r}\left[\left(1-\mathrm{e}^{-r P}\right)+T_{\mathrm{i}} g_{\mathrm{i}}\left(\mathrm{e}^{-r P}-\mathrm{e}^{-r N}\right)\right] \\
& +\frac{\left(1-T_{\mathrm{i}}\right) c}{r}\left(\mathrm{e}^{-r P}-\mathrm{e}^{-r N}\right)
\end{aligned}
$$

If individuals care only about their expected present value of compensation, an assumption which is relaxed in the empirical work, then in equilibrium, the expected present value of compensation must be equal at all institutions for equal "quality" faculty. Setting $V$ equal to a constant and differentiating, it is straightforward to show that

$$
\frac{\partial W_{P i}}{\partial \mathrm{b}_{\mathrm{i}}}<0, \quad \frac{\partial W_{P i}}{\partial \mathrm{g}_{\mathrm{i}}}<0, \quad \frac{\partial W_{P i}}{\partial \mathrm{T}_{\mathrm{i}}}<0
$$

\footnotetext{
${ }^{9}$ Institutional and individual quality differences will be accounted for in the empirical analyses.
} 
Table 1.-Starting Salaries for New Assistant Professors of Economics at Ph.D. Granting Institutions

\begin{tabular}{|c|c|c|c|c|c|c|c|c|}
\hline \multirow[b]{2}{*}{ Year } & \multicolumn{4}{|c|}{$\begin{array}{c}(\mathrm{A}) \\
\text { All New Assistant Professors }\end{array}$} & \multicolumn{4}{|c|}{$\begin{array}{c}\text { (B) } \\
\text { Those with Ph.D.s }\end{array}$} \\
\hline & $\mathrm{n}$ & Mean (Std. Dev.) & Min. & Max. & $\mathrm{n}$ & Mean (Std. Dev.) & Min. & Max. \\
\hline $1974-75$ & 45 & $13,758(1106)$ & 10,636 & 16,500 & 36 & $13,766(1214)$ & 10,636 & 16,500 \\
\hline $1975-76$ & 34 & $14,544(1177)$ & 12,375 & 17,500 & 25 & $14,711(1220)$ & 12,375 & 17,500 \\
\hline $1976-77$ & 44 & $15,456(1006)$ & 14,000 & 18,000 & 35 & $15,539(1000)$ & 14,000 & 18,000 \\
\hline $1977-78$ & 43 & $16,147(1149)$ & 13,419 & 19,450 & 36 & $16,197(1218)$ & 13,419 & 19,450 \\
\hline $1978-79$ & 40 & $16,983(1067)$ & 15,000 & 20,000 & 29 & $17,144(1174)$ & 15,000 & 20,000 \\
\hline $1979-80$ & 39 & $18,465(1253)$ & 16,500 & 21,500 & 29 & $18,627(1308)$ & 16,500 & 21,500 \\
\hline $1980-81$ & 41 & $20,081(1623)$ & 17,500 & 24,000 & 32 & $20,437(1591)$ & 17,500 & 24,000 \\
\hline
\end{tabular}

Notes: Where $\mathrm{n}$ is the number of institutions' starting salary offers reported. If an institution made offers to individuals both with and without Ph.D.s in a year, the institution would show up twice in Panel A in the year.

Source: Authors' calculations from institutional responses to the American Economics Association's Annual Survey of Economic Departments, 1974-75 to 1980-81.

That is, ceteris paribus, institutions that offer more generous benefit packages, higher growth rates of earnings between the nontenured and tenured ranks, and higher probabilities of receiving tenure will offer lower starting salaries.

\section{Descriptive Statistics}

Starting in the 1974/75 academic year, the AEA has conducted an annual survey of economics departments that requests information on the median starting salary offers accepted by new assistant professors. The AEA made the responses to these surveys available to us for the 1974/75 to $1980 / 81$ periods under the restriction that the data be kept confidential.

Response rates for departments that offered only bachelors' or masters' degrees were not always high, and many of these institutions were small and hired only a few faculty during the decade of the 1970s. The ex post tenure probabilities that can be computed for these institutions (see below) would be based on a small number of observations and would be a very imperfect measure of the ex ante tenure probabilities that a new assistant professor faced. Hence, the analyses reported in this paper are confined to the doctorate granting departments, which numbered roughly 110 during the period.

Some of these departments, however, did not regularly respond to the AEA questionnaire. Moreover, in any one year, less than half of the departments actually made offers that were accepted at the new assistant professor level to individuals who were working on their dissertations but had yet to complete them (ABDs) or who had a Ph.D. in hand. For the seven-year period, we actually have data on 286 such offers to new assistant professors-roughly 40 a year. The 286 offers came from 86 different Ph.D. granting departments. ${ }^{10}$

Table 1 presents descriptive data on these starting salaries by year. As panel A indicates, the mean median accepted salary offer rose from $\$ 13,708$ in $1974 / 75$ to $\$ 20,081$ in $1980 / 81$. The standard deviation of the offers in any year was small; less than $\$ 1200$ in most years. Depending upon one's perspective, this might reflect a highly competitive market or one in which salary collusion was prevalent. (Prior

${ }^{10}$ These departments are listed in appendix A. to 1980 the departments also reported their planned offers for the next year, and this information was distributed at the "chairmen's breakfast" at the annual AEA meetings.) It is this limited variability across institutions each year that our empirical research, presented in the next section, will seek to "explain." The small standard deviations do mask, however, the $\$ 5000$ to $\$ 7000$ range between the minimum and maximum offers that existed each year.

Each year approximately $20 \%$ to $25 \%$ of the offers went to individuals who had yet to complete their Ph.D.s (ABDs). Might some of the variation in any year simply reflect lower offers made to ABDs to provide an incentive for them to complete their degrees quickly? Panel B of table 1 provides similar descriptive statistics for the subset of offers that went to individuals who had their Ph.D.s in hand by the start of their appointment. While the mean median offers are now marginally higher, neither the standard deviation nor the range of offers changes very much. Thus, while it will be important to control for whether an offer went to a person who had a degree in hand in our empirical analyses, this variable will most likely not explain most of the variability in offers across departments.

A key premise of our study is that tenure probabilities vary across institutions, so it is important to examine whether this is true. Information on the probability of achieving tenure for new Ph.D.s hired at each department comes from a database constructed by two of us, Willis and Pieper. ${ }^{11}$ This database includes information on over 1400 individuals who both obtained a Ph.D. degree in economics from a United States department between 1970 and 1980 and, within two years of receiving their degrees, also assumed a position as an assistant professor at a United States economics department that granted either master's or doctoral degrees. The annual doctoral degree list published in the American Economic Review is the source for the new economics Ph.D. data. This list was matched against the faculty positions reported in the Economic Institute's periodic Guide to Graduate Study in Economics to determine new assistant professor appointments. The Guide includes rank by employing institution for nearly all doctoral degree

\footnotetext{
${ }^{11}$ See Willis (1990) and Willis and Pieper (1993).
} 
Table 2.-Alternative Tenure Probability Measures at Ph.D. Granting Economics Departments Faced by New Assistant Professors During THE 1970-80 PERIOD

\begin{tabular}{|c|c|c|c|c|c|c|}
\hline \multirow{2}{*}{$\begin{array}{c}\text { Tenure } \\
\text { Probability } \\
\text { Measure }\end{array}$} & \multicolumn{6}{|c|}{ Mean (Std. Dev.) [Min./Max.] } \\
\hline & All & Tier 1 & Tier 2 & Tier 3 & Tier 4 & Tier 5 \\
\hline TEN1 & $.46(.22)[0 / 1]$ & $.37(.11)[.25 / .57]$ & $.41(.18)[.20 / .51]$ & $.40(.16)[.17 / .69]$ & $.44(.50)[.14 / .81]$ & $.50(.25)[0 / 1]$ \\
\hline TEN2 & $.50(.22)[0 / 1]$ & $.37(.11)[.25 / .51]$ & $.44(.17)[.20 / .67]$ & $.44(.17)[.17 / .97]$ & $.48(.19)[.14 / .88]$ & $.54(.25)[0 / 1]$ \\
\hline TEN3 & $.41(.22)[0 / 1]$ & $.33(.13)[.21 / .57]$ & $.35(.14)[.17 / .57]$ & $.37(.14)[.17 / .62]$ & $.41(.18)[.14 / .81]$ & $.45(.25)[0 / 1]$ \\
\hline TEN4 & $.47(.22)[0 / 1]$ & $.36(.12)[.21 / .57]$ & $.40(.16)[.21 / .62]$ & $.43(.17)[.17 / .77]$ & $.46(.19)[.14 / .88]$ & $.51(.65)[0 / 1]$ \\
\hline $\mathrm{n}$ & 104 & 6 & 9 & 14 & 18 & 57 \\
\hline
\end{tabular}

Notes: Where TEN1-proportion of the 1970-1980 new assistant professors who received tenure at the institution or another institution in the same tier; TEN2-proportion of the 1970-1980 new assistant professors who received tenure at the institution or at another institution in the same or better tier; TEN3-proportion of the 1970-1980 new assistant professors who received tenure at the institution; TEN4-proportion of the 1970-1980 new assistant professors who received tenure at the institution or at a better ranked institution

Source: Authors' computations from data on the careers of economists who received Ph.D.s from American universities between 1970 and 1980 and then became assistant professors. See Willis (1990) and Willis and Pieper (1993) for details.

granting schools and a large number of master's degree granting schools. ${ }^{12}$ Sample members' academic employment histories were collected from later volumes of the Guide, supplemented by the AEA's periodic Survey of Members and by college catalogues.

From these data it is possible to compute four different measures of the proportion of newly hired assistant professors during the 1970-1980 period in each department who received tenure at the department or at one of comparable or better quality within the first eight years of receipt of their Ph.D.s. The first, TEN1, is the proportion of new assistant professors who received tenure at the institution or at another institution in the same "quality tier." Departmental equality is measured here by the Jones et al. (1982) ranking of programs and the institutions are somewhat arbitrarily grouped into the following five tiers: 1 (ranks 1-6), 2 (ranks 7-15), 3 (ranks 16-30), 4 (ranks 31-47), and 5 (all other programs). ${ }^{13}$

The second, TEN2, is the proportion of new assistant professors who received tenure at the institution or at another institution in the same, or a better, quality tier. The third, TEN3, is the proportion who received tenure at the institution itself. Finally, TEN4 is the proportion who received tenure at the institution or a better ranked one; here the actual Jones et al. ranking rather than the quality tier of the department is used in the comparisons.

TEN3 is the measure one typically thinks of when one thinks of a tenure probability. However, it is not necessarily the best measure to use in our empirical analyses. An institution that offers a 0.2 tenure probability at itself and a 0.3 probability of obtaining tenure at an equal or better quality institution may be viewed as equally or more attractive, other factors held constant, than a similar institution that offers only a 0.5 tenure probability at itself. Which tenure probability is the appropriate measure to use in empirical research is an open question.

\footnotetext{
${ }^{12}$ College catalogs and the job announcement section of the American Economic Review were used by Willis and Pieper to obtain information about new hires at institutions that were not included in an issue of the Guide.

${ }_{13}^{3}$ Willis and Pieper (1993) provide an empirical justification for these groupings.
}

In practice, as we shall see, it makes little difference because the four measures are very highly correlated across institutions. ${ }^{14}$ Table 2 presents descriptive statistics for the four tenure probability measures. Overall, the mean unweighted own tenure probability, TEN3, is 0.41 and has a standard deviation of 0.22 . The alternative measures' means are only slightly larger, the largest being TEN2 at 0.5 . This suggests that individuals who start out at one institution only infrequently find tenured positions at an equal or better quality institution.

When the institutions are broken down by tier, each of the tenure probability measures tends to increase as one moves from the highest quality to lowest quality tier. For example, the mean value of TEN3 is 0.33 at tier 1 departments but 0.45 at tier 5 departments. However, this intertier variation in mean tenure probabilities is small relative to the intratier variation across departments. Focusing on TEN3 again, this measure varies from 0.21 to 0.57 across the six tier 1 schools, and the intratier standard deviation of TEN3 ranges from 0.13 to 0.25 across tiers. Hence variations in tenure probabilities across institutions do not reflect primarily differences in institutional quality. ${ }^{15}$

\section{Econometric Estimates: New Assistant Professor Salaries}

To test whether a tradeoff did exist between starting assistant professor salaries and tenure probabilities across economics departments during the $1974 / 75$ to $1980 / 81$ period, equations are estimated of the form

$$
W_{P i t}=b_{0}+b_{1} T_{P i}+b_{2} b_{i t}+b_{3} g_{i t}+b_{4} X_{i t}+\epsilon_{i t} .
$$

Here $W_{P i t}$ is the logarithm of department I's median starting salary for new assistant professors in year $t$ during the period, $T_{P i}$ is the proportion of newly hired Ph.D.s in department I during the period that received tenure at that institution or at an institution of equal or better quality, $b_{i t}$ is the faculty benefit rate at the institution in which department

\footnotetext{
14 The lowest pairwise correlation is 0.92 .

15 Indeed, the within-tier correlation of TEN3 and a school's quality rank is less than 0.3 in absolute value for each of tiers 2 through 5.
} 
Table 3.-Determinants of the Logarithm of New Assistant Professor of Economics Starting Salaries at Ph.D. Granting Institutions: American Economic Association 1974-75 to 1980-81 SAmple (absolute value T STATISTICS)

\begin{tabular}{lccccc}
\hline \hline & $(1)$ & $(2)$ & $(3)$ & $(4)$ & $(5)$ \\
\hline TEN1 & $-.052(2.2)$ & & & & \\
TEN2 & & $-.060(2.6)$ & $-.052(2.2)$ & & \\
TEN3 & & & $-.068(3.0)$ & $-.068(2.0)$ \\
TEN4 & $-.004(4.3)$ & $-.004(4.2)$ & $-.004(4.0)$ & $-.004(4.0)$ & $-.004(2.9)$ \\
BEN & $-.214(5.5)$ & $-.215(5.6)$ & $-.220(5.5)$ & $-.222(5.7)$ & $-.201(4.6)$ \\
RASSOC & $.037(4.0)$ & $.037(4.0)$ & $.038(4.0)$ & $.037(4.0)$ & $.039(4.0)$ \\
PHD & $.029(2.6)$ & $.029(2.6)$ & $.028(2.5)$ & $.029(2.7)$ & $.036(2.1)$ \\
LMEDVAL & $.006(1.7)$ & $.006(1.8)$ & $.005(1.5)$ & $.006(1.7)$ & $.005(1.1)$ \\
TAX & $.058(3.9)$ & $.057(3.9)$ & $.057(3.9)$ & $.057(3.9)$ & $.053(4.0)$ \\
YR75 & $.117(8.3)$ & $.116(8.2)$ & $.116(8.2)$ & $.114(8.2)$ & $.111(8.6)$ \\
YR76 & $.169(12.2)$ & $.169(12.3)$ & $.169(12.2)$ & $.169(12.4)$ & $.165(13.0)$ \\
YR77 & $.232(16.5)$ & $.231(16.5)$ & $.232(16.4)$ & $.231(16.6)$ & $.226(17.7)$ \\
YR78 & $.311(22.2)$ & $.311(22.2)$ & $.311(22.1)$ & $.310(22.3)$ & $.298(23.0)$ \\
YR79 & $.384(26.9)$ & $.384(27.0)$ & $.383(26.8)$ & $.383(27.1)$ & $.381(28.9)$ \\
YR80 & $-.074(4.8)$ & $-.079(4.9)$ & $-.072(4.7)$ & $-.070(5.1)$ & $-.092(3.8)$ \\
T1 & $-.013(0.9)$ & $-.017(1.1)$ & $-.012(0.5)$ & $-.018(1.1)$ & $-.014(0.6)$ \\
T2 & $-.022(1.8)$ & $-.023(1.9)$ & $-.019(1.6)$ & $-.021(1.8)$ & $-.016(0.9)$ \\
T3 & $-.001(0.1)$ & $-.001(0.1)$ & $-.002(0.2)$ & $-.002(0.1)$ & $.004(0.2)$ \\
T4 & .808 & .809 & .808 & .811 & .821 \\
$\bar{R}^{2}$ & & & & & \\
\hline
\end{tabular}

Notes: $\mathrm{n}=263$ in all equations. Estimation in equation (5) uses an error components model in which departmental-specific random effects are assumed. All other equations are estimated by ordinary least squares.

Where: TEN1, TEN2, TEN3, and TEN4, estimated probability of gaining tenure (see Table 2 for precise definitions); BEN, benefits as a share of average salary at the university in 1979-80; RASSOC, ratio of average associate to average assistant professor salary in the department in the year; PHD, $1=$ new assistant professor had a Ph.D., 0 = ABD; LMEDVAL, logarithm of the median value of owner occupied housing in the city in 1979-80; TAX, average combined state income and sales tax rate at a $\$ 20,000$ adjusted gross income (in 1979 dollars) in the year; YRJ, $1=$ year $\mathrm{j}, 0=$ other (1974-75 is the omitted category); TJ, $1=$ department is in tier $\mathrm{j}, 0=$ other (Tier 5 is the omitted category); LNSAL, logarithm of new assistant professor starting salary in the department in the year

Sources: (A) Annual AEA Departmental Surveys-LNSAL, RASSOC, PHD; (B) American Association of University Professors (1980)-BEN; (C) U.S. Bureau of the Census (1983)-LMEDVAL; (D) Willis (1990) and Willis and Pieper (1993)-TEN1, TEN2, TEN3, TEN4; (E) National Academy of Science (1982)-T1, T2, T3, T4; and (F) Feenberg and Rosen (1986)-TAX.

I is located in year $t$, and $g_{i t}$ is the growth rate in salaries at department I that occurs when tenure is received. This growth rate is empirically specified as the ratio of average associate professor to average assistant professor salaries in the department in year $t$.

The $X_{i t}$ are vectors of other variables that are expected to influence starting salaries. The latter include estimates of the cost of living in the area in which the department is located as well as dichotomous year variables (since starting salaries vary over time), the quality tier of the institution, and the quality of the faculty that the department has hired, and whether the salary offer was to someone who had a Ph.D. in hand.

Ceteris paribus, departments will have to pay higher salaries if they are located in high cost-of-living areas or if they want to attract high-quality faculty. Conversely, higher quality departments can offer lower salaries because of the better nonpecuniary conditions of employment that they offer, such as lower teaching loads, better research support, and better colleagues and students. Faculty denied tenure at higher quality departments may also have better alternative employment opportunities than faculty denied tenure at lower quality departments, and this also will reduce the starting salary needed to attract faculty to the higher quality institutions. ${ }^{16}$

\footnotetext{
${ }^{16}$ In terms of equation (2), $c$ will be higher at high-quality institutions, and it is straightforward to show that the second cross derivative of $W_{P}$ with respect to $c$ and $T$ is positive.
}

Cost-of-living differences across areas in each year are controlled for in the analyses reported here by the logarithm of the median value of owner-occupied housing in 1979 in the city in which the institution is located and the average combined state income and sales tax at a $\$ 20,000$ adjusted gross income (in 1979 dollars) in the state in which the institution is located. ${ }^{17}$ The faculty benefit rate at the institution is obtained for $1979 / 80$, the first year that it was collected, from AAUP (1980). Not all institutions could be matched to housing value or benefit data, and the sample used in the estimation that follows is reduced to 263 observations.

Table 3 presents the estimated salary equations for the four different tenure probability measures. Turning first to the "control variables," all have the anticipated signs. Higher benefit rates $B E N$ are associated with lower starting salaries, while higher housing values $L M E D V A L$ and higher state average income and sales tax rates TAX are associated with higher starting salaries. In each of these cases, the magnitude of the relationship is smaller (in absolute value) than the one-to-one relationships that one might expect. This may reflect measurement error and the facts that housing values and tax rates are only two components of the cost of living and the benefit rate on the average salary level is not

\footnotetext{
${ }^{17}$ The average state tax rate data come from Feenberg and Rosen (1986) who compute and present these rates for the 1977-1983 period. We used their 1977 rates for the $1974 / 75$ to $1977 / 78$ data and their 1978, 1979, and 1980 rates, respectively, for data from the next three academic years.
} 
perfectly correlated with the benefit rate on new assistant professor salaries.

As expected, those institutions in which the ratio of associate to assistant professor salaries is higher (RASSOC) pay lower starting salaries. Similarly, individuals with Ph.D.s in hand received starting salaries that were roughly $3 \%$ higher than those individuals who were ABD.

Attempts to control for the quality distribution of the faculty hired by the institution by including the shares of an institution's new hires coming from the various quality tiers of doctoral programs never yielded statistically significant results. In part, this occurred because the quality tier that an institution is in is highly correlated with the quality tiers of the institutions from which it draws its faculty. In part, this occurred because the quality of, say, a Harvard Ph.D. who is hired at Yale is very different from the quality of a Harvard Ph.D. who is hired at "Podunk."

The omission of new hire quality data means that the included tier dichotomous variables capture the net effect of both departmental quality and new hire quality on starting salaries. Only the coefficients for top tier schools are statistically significant and their negative coefficients imply that, other factors held constant, top tier schools pay between $7 \%$ and $8 \%$ less than other schools.

Turning to the variables of key interest to us, the tenure probability variables, the coefficient of each proves to be negative and statistically significant from zero. The models are marginally improved when the tenure probability is defined to include receiving tenure at an equal or better quality department (TEN2, TEN4) and perform the best when "better quality" is defined to be better ranked (TEN4) instead of better tier (TEN2).

In the preferred specification (column 4), reducing the tenure probability from the mean in the sample of roughly 0.5 (see table 2) to 0 implies an increase in the starting salary for new assistant professors of roughly $3.4 \% .{ }^{18}$ Similarly, reducing the tenure probability by 0.1 implies an increase in the starting salary of only $0.68 \%$. While increases of these magnitudes may seem small, one should remember that economics is a field with excellent employment opportunities in the nonacademic sector. As noted in footnote 16, the compensating wage differential that must be paid for reduced tenure prospects will be smaller in this situation.

Several extensions warrant brief discussion here. First, one may be concerned that our ordinary least squares (OLS) estimates are inefficient and produce inconsistent standard error estimates because they assume that error terms for multiple observations in the same department are independent. As indicated in appendix A, our sample contains multiple observations for many schools. To take account of this possibility, we reestimated the model in table 3, column

${ }^{18}$ When we tested whether the marginal "implicit price" for tenure probabilities varied with the initial level of the tenure probability by including a quadratic tenure probability term in the model, the quadratic term never proved significant. Thus the assumption of only a linear effect implicit in equation (4) seems reasonable.
4, using an error components model in which departmentspecific random effects were assumed to exist. The resulting coefficients appear in column 5. They are very similar to those found in column 4 in terms of both their signs and their statistical significance.

Second, one may be concerned that our models do not control adequately for variation in the quality of assistant professors across departments within each quality tier of departments. For example, suppose that within quality tier 3 (departments ranked 16-30), department 16 recruits "better" assistant professors than department 30 and pays them the higher salaries that their greater market value requires. Suppose also that department 16 also maintains a higher tenure threshold, so much higher that its promotion rate is lower despite its higher quality of assistant professors. In this case, department 16 would simultaneously exhibit a lower promotion rate and a higher starting salary even in the absence of any compensating wage differential. Put another way, our estimate of the compensating wage differential would be biased because of our failing to adequately control for differences in faculty quality across institutions.

We do not believe this to be a serious concern because, as noted in footnote 15 , the within-tier correlations of our tenure rate variables and the departmental reputational rank are small. To test for this possibility, however, we reestimated the model in column 4, adding the reputational rank of the department as an additional explanatory variable. That is, we controlled for both the quality tier of the institution and its numerical reputational rank. When this was done, the coefficient of the tenure rate variable was unchanged.

Third, when the model was estimated separately for Ph.D.s and ABDs, the tenure probability coefficient was larger in absolute value for the ABD subsample. Given the time pressures they face in trying to complete dissertations and begin an academic career at the same time, ABDs are less likely than Ph.D.s to amass a substantial research record during their probationary period. Hence they are the ones most likely to feel the adverse impact of low tenure probabilities and thus to receive the larger compensating wage differentials.

Fourth, when the model was reestimated with the data stratified by higher (tiers 1-4) and lower (tier 5) quality departments, the tenure probability coefficient was largest in absolute value for the lower quality departments. Alternative employment opportunities in both the academic and nonacademic sectors are likely to be better for people denied tenure at the higher quality schools than for those denied tenure at the lower quality schools. Thus it is at the lower quality schools that the compensating wage differentials for tenure probabilities will be larger.

Fifth, when the model was reestimated with the data stratified by early (1974/75 to $1977 / 78)$ and later (1978/79 to 1980/81) years during the period, the tenure probability coefficient was larger in absolute value during the latter period and close to -0.1 during that time. The market for faculty was one of weak relative demand during the 
mid-1970s as real academic salaries declined, and it was only during our second period that relative demand tightened and real faculty salaries began to grow. ${ }^{19}$ Thus our finding here is consistent with the belief that compensating wage differentials will be larger when labor markets are relatively tight.

Finally, a referee has suggested to us that our constructed tenure probability variables measure the true subjective tenure probabilities faced by new assistant professors with error because the constructed tenure probability variables often were based on a small number of observations. While the mean number of new assistant professors in our sample hired by a department during the period was close to 10 , one-tenth of the departments hired four or fewer assistant professors. Hence measurement error in the tenure probability variables may well be present. If measurement error was random, the coefficients of the tenure probability variables in table 3 would be biased toward zero and the table 3 estimates would understate the impact of tenure probability differences on starting salaries.

To take account of this problem, an instrument for each of the tenure probability variables was obtained. ${ }^{20}$ When the model was reestimated using the instrumental-variable estimate for each tenure probability variable, rather than the actual value, in each case the estimated tenure probability coefficient in the salary equation did become larger in absolute value. ${ }^{21}$ However, the statistical significance of the coefficients was also reduced.

\section{Econometric Estimates: Tenured Faculty Salaries}

Lower tenure probabilities for assistant professors imply either that a department will have fewer tenured faculty in steady state or that it will hire a greater share of its tenured faculty from faculty already employed at other institutions. Tenured faculty hired away from other institutions typically earn more than tenured faculty promoted from within because the former must be induced to leave their original institution and compensated for the monetary and psychological costs of mobility that they face.

To the extent that lower tenure probabilities for assistant professors do imply a greater share of tenured faculty hired

\footnotetext{
${ }^{19}$ See American Association of University Professors (1997, fig. 1).

${ }^{20}$ The instruments for each tenure probability variable were obtained from equations that included the selectivity of the institution, as measured by its Barron's (1982) rating (broken into six selectivity classes), the institution's student-faculty ratio, the percentage of the institution's faculty members that had Ph.D. degrees, and all of the exogenous variables from table 3 , except for the year and departmental quality dichotomous variables.

${ }^{21}$ Specifically, the coefficients and standard errors of the tenure probability variables changed as indicated:

$\begin{array}{lcccc} & \text { TEN1 } & \text { TEN2 } & \text { TEN3 } & \text { TEN4 } \\ \begin{array}{c}\text { Table 3 } \\ \text { estimate }\end{array} & -0.052(2.2) & -0.060(2.6) & -0.052(2.2) & -0.068(3.0) \\ \begin{array}{c}\text { Instrumental- } \\ \text { variable } \\ \text { estimate }\end{array} & -0.088(1.6) & -0.067(1.0) & -0.090(1.5) & -0.069(1.0)\end{array}$
}

Table 4.-Determinants of the Logarithm of Average Associate Professor Salaries and the Ratio of Average Associate to Average Assistant Professor Salaries in Economics Departments at Ph.D. GRANTING INSTITUTIONS: AMERICAN ECONOMIC ASSOCIATION 1974-75 TO 1980-81 SAMPLE (ABSOLUTE VAlue T STATISTICS)

\begin{tabular}{lllll}
\hline \hline \multicolumn{4}{c}{ Tenure Probability Coefficients } \\
\cline { 2 - 5 } & TEN1 & TEN2 & TEN3 & TEN4
\end{tabular}

A) Logarithm of

Associate Professor Salaries ${ }^{\mathrm{a}}$

1) Actual Tenure Probability

2) Predicted Tenure Probability $\begin{array}{llll}-.040(1.4) & -.044(1.5) & -.032(1.1) & -.044(1.6) \\ -.307(5.1) & -.326(5.0) & -.377(6.5) & -.397(6.0) \\ .729 & .750 & .773 & .763\end{array}$

B) Ratio of Average Associate to Average Assistant Professor Salaries $^{\mathrm{b}}$

1) Actual Tenure Probability

2) Predicted Tenure $\begin{array}{lllll}\text { Probability } & -.530(8.0) & -.572(7.6) & -.616(9.8) & -.636(8.6)\end{array}$ $\begin{array}{lllll}\overline{\mathrm{R}}^{2} & .288 & .258 & .387 & .301\end{array}$

Notes: a Also included in each equation were all of the variables from Table 3 save for PHD and RASSOC.

b Also included in each equation were year and tier dichotomous variables.

from the external market, we should therefore expect to observe a negative relationship between assistant professors' tenure probabilities and the salaries of tenured faculty, in a department, other factors held constant. Moreover, the tenure probability measure most closely related to tenured faculty members' salaries in this case is likely to be TEN3, the probability of receiving tenure at the institution itself. Furthermore, the relevant tenure probability variable here is the actual, ex post tenure probability, since it is this variable that may influence the fraction of associate professors hired from the external market.

Expected tenure probabilities may also influence the salaries of associate professors who are promoted from within a department. In particular, low expected tenure probabilities may induce new assistant professors to work harder so that if they fail to get tenure, they will be worth more to other departments. This increased effort should also increase their productivity at their original department and hence their salaries if they are promoted. Put another way, low expected tenure probabilities, can be thought of as being part of tournaments with greater rewards for winning. ${ }^{22}$ This suggests that the expected tenure probabilities, as measured by the instruments for tenure probabilities that we have obtained, should also be included in tenured faculty members' salary equations and that we should expect to observe a negative relationship between these variables and tenured faculty salaries as well.

Panel A of table 4 uses data from the AEA annual salary survey on average salaries for associate professors of

${ }^{22}$ See Lazear and Rosen (1981). In terms of the model used in this paper, the implication of their model is that $g_{i}$ and $C_{i}$ should be inversely related to $T_{i}$. 
economics to test these hypotheses. Equations similar to equation (4) are estimated, save that the logarithm of the average associate professor salary is now the dependent variable, both the actual and estimated tenure probability variables are included in the equation, and the new Ph.D. variable $(P H D)$ and the ratio of average associate to average assistant professor salaries (RASSOC) are excluded from the analyses. The coefficients for the various tenure probability variables are found in panel A of the table.

Quite strikingly, lower tenure probabilities for assistant professors are associated, other factors held constant, with higher salaries for associate professors, and TEN3 is the best performing tenure probability variable. This association is statistically significantly different from zero, however, only for the predicted tenure probability variables not the actual ones. Hence, the primary route that low tenure probabilities raise associate professor salaries is through their effects on assistant professor effort/productivity, not through compensating wage differentials that must be paid to attract associate professors from the external market.

Including the reputational rank of the department, in addition to its tier, to better control for differences in the quality of associate professors across institutions, does not change the magnitude or statistical significance of this relationship. Reducing TEN3 from its mean in the sample of roughly 0.4 (table 2) to 0 implies an increase in the average associate professor salary of roughly $12 \%$. Similarly, reducing this tenure probability by 0.1 implies an increase in the average salary of associate professors of roughly $2.2 \%$. Lower tenure probabilities for assistant professors in a department thus lead to increases in both new assistant professor and average associate professor salaries. ${ }^{23}$

Of course, these analyses suggest that the estimates in table 3 , which treat the ratio of average associate to average assistant professor salaries as predetermined may overstate the extent to which changes in tenure probabilities influence new assistant professor salaries. To see why this is true, panel B of table 4 shows the tenure probability coefficients that result when the ratio of average associate to average assistant professor salaries RASSOC was regressed on each tenure probability and a set of year and tier dichotomous variables. In each case, the tenure probability coefficients are negative, again primarily for the predicted rather than actual tenure probability variable, implying that higher tenure probabilities imply lower growth rates of salary across ranks.

\footnotetext{
${ }^{23}$ A similar tradeoff does not appear in these data between the average salary of full professors in a department and the tenure probabilities faced by assistant professors. We believe that this is due to measurement error problems induced by our inability to control for differences in the seniority distribution of full professors across departments. This is less of a problem with the data on the average salaries of associate professors, since most people spend less than six years in this rank.
}

Returning to equation (4), it is straightforward to show that

$$
\frac{\partial W_{P i}}{\partial T_{P i}}=b_{1}+\frac{b_{3} \partial g_{i}}{\partial T_{P i}}
$$

where $g_{i}$ equals $R A S S O C$. Since $b_{3}$ is always less than zero in table 3 , it follows that the tenure probability coefficients in table 3 overstate (in absolute value) the magnitude of the tradeoff between new assistant professor salaries and the tenure probabilities that they face.

Put another way, these results suggest that the cost to an economics department of unilaterally reducing the tenure probability that its assistant professors faced during the 1970s was not primarily the higher salaries that it had to pay to attract new assistant professors. Rather, it was the higher salaries it had to pay because of the higher productivity such an action induced for the tenured associate professors it promoted and tenured from within. ${ }^{24}$

\section{Concluding Remarks, Qualifications, and Extensions}

The analyses of the previous sections provided estimates of the likely impact on starting faculty salaries and tenured faculty salaries at institutions that unilaterally decide to substantially reduce the probabilities that new assistant professors ultimately receive tenure at them, if only a small number of institutions make such changes. However, analyses of this type cannot provide any evidence on what the likely impact of substantially changing the average probability (across institutions) of a new assistant professor's receiving tenure would be on the average salary that academic institutions must pay. ${ }^{25}$ To answer the latter question requires evidence on how changes in average tenure probabilities influence the distribution of new Ph.D.s between the nonacademic and academic sectors and how they affect the willingness of potential Ph.D. students to embark upon and complete Ph.D. studies.

While a number of empirical studies have addressed the determinants of the supply of new doctorates in the aggregate (see the summary in Ehrenberg (1992)) and a smaller number have addressed the decisions by new Ph.D.s whether

\footnotetext{
${ }^{24} \mathrm{~A}$ referee has expressed the concern that our analyses of associate professor salaries may be contaminated by a number of institutions not giving tenure to faculty until they achieve full professor rank. The mean proportion of associate professors with tenure in our sample was 0.8 across the 87 institutions in the sample in the early 1980s (American Association of University Professors (1982), with only 5 institutions' proportion of associate professors with tenure falling below 0.5 (Carnegie Mellon, Harvard, Johns Hopkins, Wyoming, and Yale). Exclusion of the observations from these institutions from the sample and reestimation of the models underlying table 4 yielded a similar pattern of results to those reported in the table.

${ }^{25}$ Our analyses also do not indicate what would happen to an individual department that unilaterally opted out of the tenure system altogether. Presumably such a department would not only reduce the tenure rate to zero, but would also eliminate the "up or out" feature of the tenure system. Removing the prospect of tenure would be viewed as "bad" by prospective new faculty, but removing the "out" part of "up or out" would be viewed as good. Hence the net effect on starting salaries would be indeterminate.
} 
to accept employment in the academic or nonacademic sectors (e.g., Hansen et al. (1980), Stapleton (1989), Freeman (1975)), none have addressed the role of tenure probabilities in these decisions. Future research should attempt to conceptualize more fülly the role that tenure probabilities play in influencing the aggregate supply of new Ph.D.s, the allocation of these Ph.D.s across academic and nonacademic employment, and academic salary levels and then, if possible, to estimate these relationships.

It would also be worthwhile for researchers to replicate the analyses described above for a field which has less promising nonacademic employment opportunities than does economics. One would expect to find compensating wage differentials for tenure probabilities higher in fields with poorer nonacademic employment opportunities. That is, the estimates presented in this paper may well understate the impact of changing tenure probabilities in fields with less promising nonacademic employment opportunities.

Our estimates used salary data for the $1974 / 75$ to $1980 / 81$ period. This period was dictated by the availability of tenure probability data and the willingness of the AEA to provide us with salary data. However, much of this period was a period of excess supply in the academic labor market in which real academic salaries fell. Compensating wage differentials for undesirable job characteristics, such as low tenure probabilities, are likely to be smaller in periods of excess supply than they are in periods of tight labor markets. Thus our estimates likely understate the impact of changing tenure probabilitie in periods when the labor market for faculty is tight, such as has been projected by some for the years ahead. ${ }^{26}$

Finally, we must stress that the implications that we have drawn about how a change in tenure probabilities by a small number of departments would affect those departments' starting salaries all assume that the starting salary-tenure probability relationship that we have estimated is due to our postulated hypothesis. However, our attempts to control for the quality of an institution's new hires by including the distribution of its new hires across quality tiers of institu. tions as explanatory variables (see section IV) may well be inadequate. We thank the editors and an anonymous referee for cautioning us on this point. There is tremendous variation in the quality of students seeking employment from each graduate program in any one year. The quality of is Cornell $\mathrm{PhD}$ student who is hired at Harvard, for example, is likely to be very different than the quality of a Cornell $\mathrm{PhD}$ student hired at "Podunk." Our inability to finely control for the quality of new hires at each institution leaves open the possibility that our results reflect unobservable quality differences rather than compensating salary differences fo different tenure probabilities.

Two possible approaches exist to trying to rule out this alternative hypothesis. One would be to obtain data on each department's rankings of its graduate students and use this, as well as the ratings of graduate department, to better

${ }^{26}$ See, for example, Bowen and Sosa (1989). control for the quality of each department's new assistant professor hires. A second would be to develop data for a second period, to assume that the unobserved quality of each department's new hires did not vary much over time and then estimate models of the change in each institution's starting salaries for assistant professors as a function of the changes in its tenure probability, quality ranking, and so on. That is, one could use a fixed-effects model to try to eliminate any unobservable differences in the quality of new assistant professors across departments. Neither of these solutions is feasible given the data we currently have, but future research should consider them. Our own prior is that it will be a lot easier to implement the second approach than the first.

\section{REFERENCES}

American Association of University Professors, "The Annual Report on the Economic Status of the Profession," Academe $66-(1980)$, 285-307.

"The Annual Report on the Economic Status of the Profession," Academe 68 (1982).

"Not So Good: The Annual Report on the Economic Status of the Profession," Academe 83 (1997), 12-37.

Barron's Educational Series, Barron's Profiles of American Colleges, 13th ed. (Great Neck, NY: Barron's, 1982).

Bennett, Amanda, "Many Decry It, Few Deny It," Wall Street Journal (Oct. 10, 1994).

Bowen, William G., and Julie Ann Sosa, Prospects for Faculty in the Arts and Sciences (Princeton, NJ: Princeton University Press, 1989).

Carmichael, Lorne, "Incentives in Academia: Why Is There Tenure?," Journal of Political Economy 96 (1988), 453-472.

$\rightarrow$ Ehrenberg, Ronald G., "The Flow of New Doctorates," Journal of Economic Literature 30(1992), 830-875.

Ehrenberg, Ronald G., and Robert S. Smith, Modern Labor Economics: Theory and Public Policy, 6th ed. (Reading, MA: Addison-Wesley, 1997).

Feenberg, Daniel R., and Harvey S. Rosen, "State Personal Income and Sales Taxes, 1977-1983," in Harvey Rosen (ed.), Studies in State and Local Public Finance (Chicago: University of Chicago Press, 1986)

Hamermesh, Daniel S., "Aging and Productivity, Rationality and Matching: Evidence from Economists," National Bureau of Economic Research Working Paper 4906 (1994).

Freeman, Richard. "Supply and Salary Adjustments in the Changing Scientific Manpower Market: Physics 1998-73," American Economic Review, 65 (1975), 27-39.

Hammond, P. Brett, and Harriet P. Morgan (eds.), Ending Mandatory Retirement for Tenured Faculty: The Consequences for Higher Education (Washington, DC: National Academy Press, 1991).

$\rightarrow$ Hansen, W.L., H.B. Newburger, F.J. Schroder, D.C. Stapleton, and D.J. YoungDay. "Forecasting the Market for New Ph.D. Economists," American Economic Review 70 (1980), 49-63.

Henderson, Keith, "Bennington Remakes Itself Decisively," Christian Science Monitor (Aug. 29, 1994).

Jones, Lyle V., Gardner Lindzey, and Porter E. Coggeshall (eds.), An Assessment of Research-Doctorate Programs in the United States (Washington, DC: National Academy Press, 1982).

Lazear, Edward, "Why Is There Mandatory Retirement?," Journal of Political Economy 87 (1979), 1261-1285.

$\rightarrow$ Lazear, Edward, and Sherwin Rosen, "Rank Order Tournaments as Optimum Labor Contracts," Journal of Political Economy 89 (1981), 841-865.

$\rightarrow$ Levin, Sharon G., and Paula E. Stephan, "Research Productivity over the Life Cycle" Evidence for Academic Scientists," American Economic Review 81 (1991), 114-132.

McPherson, Michael, and Gordon Winston, "The Economics of Academic Tenure: A Relational Perspective," in Michael McPherson, Morton Schapiro, and Gordon Winston (eds.), Paying the Piper: Productiv- 
ity, Incentives, and Financing in U.S. Higher Education (Ann Arbor, MI: University of Michigan Press, 1993).

$\rightarrow$ Ransom, Michael R., "Seniority and Monopsony in the Academic Labor Market," American Economic Review 83(1993), 221-233.

Rees, Albert, and Sharon Smith, Faculty Retirement in the Arts and Sciences (Princeton, NJ: Princeton University Press, 1991).

Siow, Aloysius, "The Organization of the Market for Professors," mimeo, University of Toronto Economics Department (1994).

$\rightarrow$ Stapleton, David C. "Cohort Size and the Academic Labor Market," Journal of Human Resources 24 (1989), 221-252.

Stephan, Paula, and Sharon G. Levin, Striking the Mother Lode in Science: The Importance of Age, Place, and Time (New York: Oxford University Press, 1992).
Stigler, George, "An Economic Episode," in George Stigler (ed.), The Intellectual and the Market Place (Cambridge, MA: Harvard University Press, 1984).

U.S. Bureau of the Census, County and City Data Book (Washington, DC: US Government Printing Office, 1983).

Willis, Rachel A., Academic Labor Markets: A Study of Academic Placement and Tenure for Doctoral Economists, Ph.D. dissertation, Northwestern University, Evanston, IL (1990).

Willis, Rachel A., and Paul J. Pieper, "Gender Differences in Promotion for Academic Economists," presented at the Western Economic Association Conference, Lake Tahoe, NV (June 1993).

Table A1.-Number of Observations on New Assistant Professors' Salaries at' Ph.D. Granting Institutions DuRING the 1974/75 to 1980/81 Period Used IN THE ANAlyses ${ }^{\mathrm{a}}$

\begin{tabular}{|c|c|c|c|}
\hline Department & $\begin{array}{l}\text { Number of } \\
\text { Observations }\end{array}$ & Department & $\begin{array}{l}\text { Number of } \\
\text { Observations }\end{array}$ \\
\hline The American University & 1 & University of Hawaii & 1 \\
\hline Arizona State Univ. & 8 & University of Houston & 1 \\
\hline University of Arkansas & 1 & University of Illinois & 4 \\
\hline Boston College & 3 & Indiana University & 3 \\
\hline Boston University & 2 & University of Iowa & 1 \\
\hline Brown University & 2 & Iowa State University & 6 \\
\hline Univ. of California & 3 & Johns Hopkins University & 2 \\
\hline Univ. of California-Davis & 5 & University of Kansas & 7 \\
\hline Univ. of Cal.-Los Angeles & 2 & University of Kentucky & 6 \\
\hline Univ. of Cal.-San Diego & 3 & Louisiana St. Univ.-Baton Rouge & 5 \\
\hline Univ. of Cal.-Santa Barbara & 2 & University of Maryland & 1 \\
\hline Carnegie Mellon & 2 & Massachusetts Inst. of Tech. & 3 \\
\hline University of Chicago & 1 & University of Michigan & 4 \\
\hline Clark University & 2 & Michigan State University & 5 \\
\hline Univ. of Colorado & 1 & Univ. of Minnesota-Minneapolis & 2 \\
\hline Colorado State Univ. & 2 & University of Mississippi & 1 \\
\hline Univ. of Connecticut & 1 & University of Missouri & 6 \\
\hline Cornell University & 3 & University of Nebraska & 2 \\
\hline Duke University & 3 & Univ. of North Carolina & 2 \\
\hline Univ. of Florida & 5 & North Carolina State Univ. & 4 \\
\hline Florida State Univ. & 1 & Northwestern University & 3 \\
\hline George Washington Univ. & 3 & University of Notre Dame & 4 \\
\hline Georgetown University & 1 & Ohio State University & 4 \\
\hline University of Georgia & 4 & University of Oklahoma & 3 \\
\hline Georgia State Univ. & 3 & Oklahoma State Univ. & 4 \\
\hline Harvard University & 2 & Northeastern University & 5 \\
\hline University of Oregon & 4 & Syracuse University & 5 \\
\hline Univ. of Pennsylvania & 5 & Temple University & 6 \\
\hline Pennsylvania State Univ. & 5 & University of Tennessee & 1 \\
\hline University of Pittsburgh & 2 & University of Texas & 5 \\
\hline Princeton University & 6 & Texas A\&M University & 6 \\
\hline Purdue University & 3 & Tulane University & 2 \\
\hline Rice University & 2 & University of Utah & 1 \\
\hline University of Rochester & 2 & Vanderbilt University & 2 \\
\hline Rutgers University & 3 & University of Virginia & 10 \\
\hline St. Louis University & 4 & Virginia Polytechnic Inst. & 2 \\
\hline Univ. of South Carolina & 3 & University of Washington & 5 \\
\hline Univ. of Southern California & 5 & Washington State Univ. & 2 \\
\hline Southern Illinois University & 1 & Washington University & 2 \\
\hline Southern Methodist University & 5 & Wayne State University & 5 \\
\hline Stanford University & 6 & Univ. of Wisconsin-Madison & 5 \\
\hline SUNY at Albany & 2 & University of Wyoming & 2 \\
\hline SUNY at Binghamton & 1 & Yale University & 5 \\
\hline SUNY at Buffalo & 6 & & \\
\hline
\end{tabular}

Note: * 86 Ph.D. granting departments provided 286 observations on starting assistant professor salaries during the 1974-75 to 1980-81 period. 